\title{
Benchmark No-Wash Dyes for Calcium Flux Measurement
}

BioTechniques 34:164-166 (January 2003)

Calcium flux measurement has become a key method in the investigation of G-protein coupled receptors (3). Central to this technique is the use of cell-permeable fluorescent dyes, such as Fluo-4, which increase in fluorescence markedly upon influx of calcium through membrane channels or release from intracellular stores (5). About $40 \%$ of G-protein coupled receptors (GPCRs) utilize G-proteins that stimulate calcium flux as a cellular signaling mechanism, and those that do not can be artificially coupled to calcium flux through the use of promiscuous G proteins (such as $\mathrm{G} \alpha_{16}$ ) or through the use of chimeric $G$ proteins $(4,9,11)$. Stimulation of dye-loaded cells with ligand leads to a transient increase in fluorescence, a system that has proven applicability with a wide variety of GPCRs.

This technique has gained great favor in the pharmaceutical industry with the introduction of high-throughput equipment that allows for the parallel processing of samples and a throughput of thousands of assays per day $(7,8,12)$. Because one is looking at a functional readout, antagonists may be found that are acting in a noncompetitive manner; such compounds would be missed in a standard radioligand binding assay. In addition, calcium flux measurement is one of the fundamental techniques used to "de-orphanize" receptors, as the use of a functional readout allows for screening for agonists in cases where the natural ligand is unknown $(7,8)$.

The essential technical hurdle in the use of calcium flux dyes is that the intracellular concentration of calcium is considerably lower than that found outside the cells. Early calcium flux protocols required that the cells be washed extensively after incubation with fluorescent dye, as extracellular dye resulted in an unacceptably high background fluorescence (3). Because the fluorescence is monitored through the bottom of the well, confluent monolayers of cells are required, and washing of all but the most tenacious cells frequently results in the detachment of cells and spuriously low readings. The introduction of new, no-wash dyes has changed this situation, although the dyes are quite expensive and the composition of the dyes is a trade secret.

The use of trypan blue and hemoglobin to quench background fluorescence has a long history in microscopy $(6,13)$, and it was postulated that these dyes could effectively serve to quench background fluorescence. U373 cells and HT-29 cells, which express neurokinin1 (substance P) and neurotensin (NT-1) receptors, respectively, were employed as model systems $(1,2)$. Experimentation has revealed that either trypan blue or hemoglobin can be employed, allow- ing for the use of no-rinse dyes with a defined composition at about a hundredth the cost of commercially available preparations.

Trypan blue, probenecid, and hemoglobin were purchased from Sigma (St. Louis, MO, USA). BSA was purchased from Fisher (Houston, TX, USA), Hank's and HEPES were purchased from Invitrogen (Carlsbad, CA, USA). Fluo-4 was purchased from Molecular Probes (Eugene, OR, USA). Cell lines were purchased from the ATCC (Manassas, VA, USA) and grown according to ATCC guidelines. No-wash calcium dye, the FLIPR ${ }^{\circledR}$ Calcium Assay Kit, was purchased from Molecular Devices (Sunnyvale, CA, USA) and prepared according to the manufacturer's directions. Substance $\mathrm{P}$ and Neurotensin were purchased from Bachem Bioscience (King of Prussia, PA, USA).

See Table 1 for preparation of 100 $\mathrm{mL} 2 \times$ dye solution (enough dye for 20 96-well plates).

When setting up a small number of plates, it is suggested that spent medium be removed by quick inversion. Add the dye, $100 \mu \mathrm{L} /$ well, diluted 50/50 with the same media in which the cells grow. Higher-throughput applications can be facilitated by aspirating the media from the cells down to the $50-\mu \mathrm{L}$ level and adding $50 \mu \mathrm{L} 2 \times$ dye. Cells should be allowed to remain in this stain for between $45 \mathrm{~min}$ and $3 \mathrm{~h}$ before use. Probenecid, an anion transport inhibitor, is used to slow the process of dye extrusion from the cells.

A FLIPR 384, outfitted with a 96-tip head, was employed for all of these ex- 
Table 1. Preparation of $2 \times$ Dye Solution

\begin{tabular}{|c|c|}
\hline Component & Final Concentration \\
\hline 4 mL 1 M HEPES & $40 \mathrm{mM}$ \\
\hline $1 \mathrm{gBSA}$ & $1 \%$ \\
\hline $142 \mathrm{mg}$ probenecid pre-dissolved in $1 \mathrm{~mL} 1 \mathrm{M} \mathrm{NaOH}^{*}$ & $5 \mathrm{mM}$ \\
\hline $\begin{array}{l}20 \mathrm{~mL} 0.4 \% \text { trypan blue solution (10×) OR } 0.4 \mathrm{mg} \\
\text { hemoglobin }\end{array}$ & $\begin{array}{l}0.04 \% \text { OR } \\
0.004 \%\end{array}$ \\
\hline $\begin{array}{l}250 \mu \mathrm{g} \text { Fluo-4 diluted in } 57 \mu \mathrm{L} \text { DMSO and } 57 \mu \mathrm{L} 20 \% \\
\text { pluronic acid }\end{array}$ & $2 \mu \mathrm{M}$ \\
\hline \multicolumn{2}{|l|}{ Hank's to $100 \mathrm{~mL}$ final volume } \\
\hline *Probenecid solution should be made on the day it is $t$ & \\
\hline
\end{tabular}

periments. A dose-response of ligand in $0.1 \%$ BSA/Hank's at three times the final concentration was used as the source plate. Fluorescence of the cells was monitored at 2-s intervals as $50 \mu \mathrm{L}$ ligand were added. Graphs were generated from the peak fluorescence values obtained minus the baseline fluorescence. different dye systems in a dose three different dye systems in a doseresponse of substance P-stimulated calcium flux on U373 cells. Figure 2 illustrates the same kind of calcium flux stimulation using neurotensin on HT-29 cells. The trypan blue and hemoglobin dyes provide a signal-to-noise ratio that is equal to or better than that achieved with the commercial dye.

The concentrations of Fluo-4, probenecid, trypan blue, and hemoglobin were titered over a wide range to determine the optimum concentrations provided in Table 1 (data not shown).

It has been observed that the trypan blue dye system works well for most receptors, but it failed to work on chemokine receptors (data not shown). In these cases, hemoglobin can be used. It may be that the highly charged nature of trypan blue causes it to interact nonspecifically with some classes of receptors. Other than this caveat, these dye systems have proven to be generally useful for a wide range of cell types and both endogenous and overexpressed receptors (data not shown).

As long as the quenching dyes are relatively nontoxic, do not penetrate into live cells, and overlap reasonably well with the excitation/emission wave- 


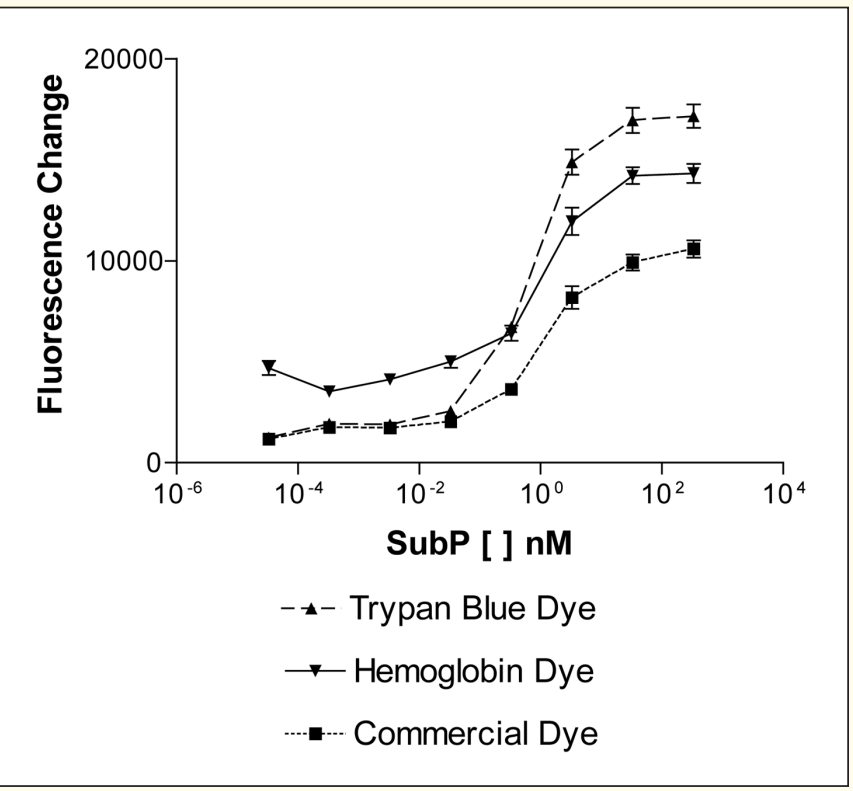

Figure 1. Substance P-stimulated calcium flux. A dose-response of substance P-stimulated calcium flux in U373 cells using a commercially available kit and the two dye systems detailed in the text. Fluorescence change is defined as (Peak-Baseline). The values above are $\overline{\mathrm{x}} \pm$ SD for four replicates at each data point. Shown is a representative example of an experiment run three times with similar results.

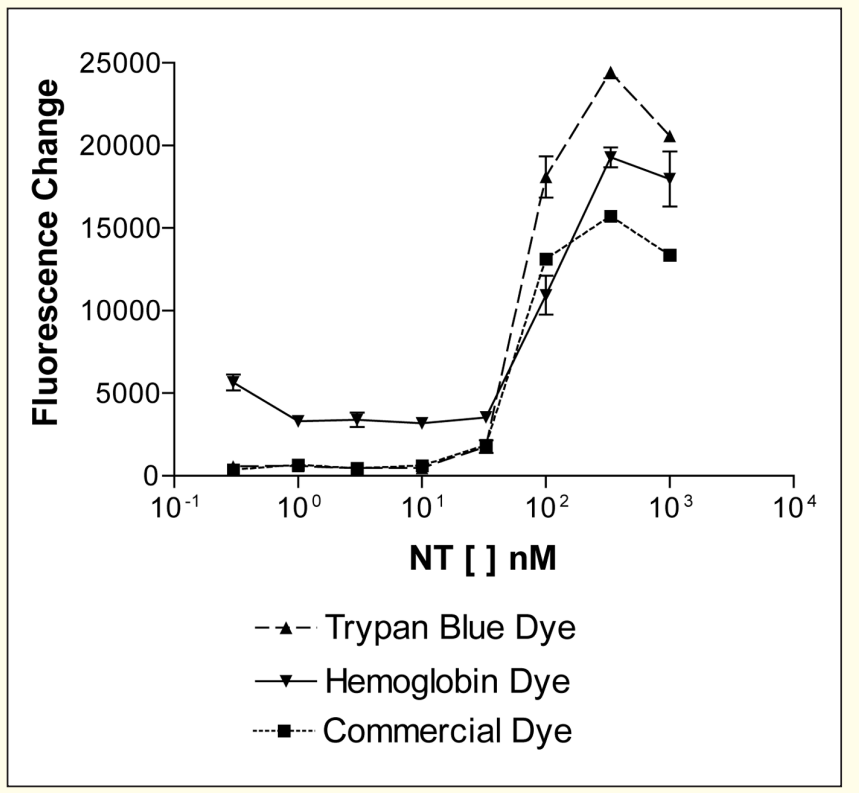

Figure 2. Neurotensin-stimulated calcium flux. A dose-response of neurotensin-stimulated calcium flux in HT-29 cells using a commercially available kit and the two dye systems detailed in the text. Fluorescence change is defined as (Peak-Baseline). The values above are the $\overline{\mathrm{x}} \pm$ SD for four replicates at each data point. Shown is a representative example of an experiment run three times with similar results. lengths of the calcium indicator in use, it seems likely that many dyes could be used for the purpose of quenching background fluorescence in calcium flux assays. The dyes chosen for these experiments were picked in large part because they are common and inexpensive, but it will be interesting to see where further investigation into background-quenching dyes leads.

\section{REFERENCES}

1.Bordey, A., P. Feltz, and J. Trouslard. 1994 Mobilization of intracellular calcium by substance $\mathrm{P}$ in a human astrocytoma cell line (U373 MG). Glia 11:277-283.

2.Bozou, J.C., N. Rochet, I. Magnaldo, J.P. Vincent, and P. Kitabgi. 1989. Neurotensin stimulates inositol trisphosphate-mediated calcium mobilization but not protein kinase $\mathrm{C}$ activation in HT29 cells. Involvement of a Gprotein. Biochem. J. 264:871-878.

3.Cerione, R.A. 1994. Fluorescence assays for G-protein interactions. Methods Enzymol. 237:409-423.

4.Coward, P., S.D. Chan, H.G. Wada, G.M. Humphries, and B.R. Conklin. 1999. Chimeric $\mathrm{G}$ proteins allow a high-throughput signaling assay of Gi-coupled receptors. Anal. Biochem. 270:242-248.

5.Gee, K.R., K.A. Brown, W.N. Chen, J. Bishop-Stewart, D. Gray, and I. Johnson. 2000. Chemical and physiological characterization of fluo-4 $\mathrm{Ca}(2+)$-indicator dyes. Cell Calcium 27:97-106.

6.Hansson, Y., E. Jacobson, J. Ortlund, S. Paulie, and P. Perlmann. 1987. A rapid method for detection of cellular proliferation using carboxyfluorescein. Assay of growth factors (IL-2, IL-1) and growth inhibiting antibodies. J. Immunol. Methods 100:261-267.

7.Howard, A.D., S.D. Feighner, D.F. Cully, J.P. Arena, P.A. Liberator, C.I. Rosenblum, M. Hamelin, D.L. Hreniuk, et al. 1996. A receptor in pituitary and hypothalamus that functions in growth hormone release. Science 273:974-977.

8.Kojima, M., R. Haruno, M. Nakazato, Y. Date, N. Murakami, R. Hanada, H. Matsuo, and K. Kangawa. 2000. Purification and identification of neuromedin $U$ as an endogenous ligand for an orphan receptor GPR66 (FM3). Biochem. Biophys. Res. Commun. 276:435-438.

9.Kostenis, E. 2001. Is G $\alpha 16$ the optimal tool for fishing ligands of orphan G-protein-coupled receptors? Trends Pharmacol. Sci. 22:560-564.

10.Merritt, J.E., S.A. McCarthy, M.P. Davies, and K.E. Moores. 1990. Use of fluo-3 to measure cytosolic $\mathrm{Ca}^{2+}$ in platelets and neurophils. Loading cells with the dye, calibration of traces, measurements in the presence of plasma, and buffering of cytosolic $\mathrm{Ca}^{2+}$. Biochem. J. 269:513-519.

11.Milligan, G. and S. Rees. 1999. Chimaeric G $\alpha$ proteins: their potential use in drug discovery. Trends Pharmacol. Sci. 20:118-124.

12.Sullivan, E., E.M. Tucker, and I.L. Dale. 1999. Measurement of $[\mathrm{Ca} 2+]$ using the Fluorometric Imaging Plate Reader (FLIPR).
Methods Mol. Biol. 114:125-133.

13.Wan, C.P., C.S. Park, and B.H. Lau. 1993 A rapid and simple microfluorometric phagocytosis assay. J. Immunol. Methods 162:1-7.

Received 21 June 2002; accepted 9 September 2002.

Address correspondence to:

Dr. Christopher Mehlin Box 357350

University of Washington

Seattle, WA 98195, USA

e-mail:cmehlin@u.washington.edu 